\title{
Pulmonary blastoma in an adult male
}

\section{Introduction}

Pulmonary blastoma is one of the rare lung tumors and is considered to be dissnct from other lung tumors by its pathological features, clinical course and prognosis. ${ }^{1}$ Classic pulmonary blastoma is composed of both malignant mesenchymal stroma and epithelial components resembling embryonic lung tissue. Surgery is the standard treatment and the efficacy of adjuvant chemotherapy and radiotherapy has not yet been established. ${ }^{2}$

Keywords: pulmonary, chest, examinations, pathology, anesthesia, tumors, lung, surgery, heterogeneous

\section{Case report}

Our patient was admiied and managed at Abassia Pulmonary Hospital, Ministry Of Health, Cairo Governorate, Egypt. A 37 yearold Egyptian male presented to our hospital with repeated attacks of blood singed sputum. The first attack dated about 6 months before admission. The patient had progressive shortness of breath over a period of two years. The patient was a smoker of one pack of Cigarettes per day for more than 15 years. There was no significant past history or family history.

Aare admission to the Chest Medicine Department at Abbasia Pulmonary Hospital, routine basic investigations were done including complete blood picture with differensal count, facing blood sugar and 2 hours aaer meal, liver funcson tests, renal funcson tests, and coagulason profile. All investigations were within normal. Sputum examinations for AFB for 3 successive days were done and were all negative. Sputum cytology did not show malignant cells.

The P-A view of his chest X-ray showed a well-demarcated right upper and middle lung zones mass. The mass extends to the right lung apex abuung the inner chest wall and medially extended to the mediassnum and the right hilum. The mass has a heterogeneous texture (Figure 1). Chest CT scan (Figure 2) showed a large well defined, heterogeneous right upper lobe mass. The CT showed no significant meditasonal lymph nodes enlargement.

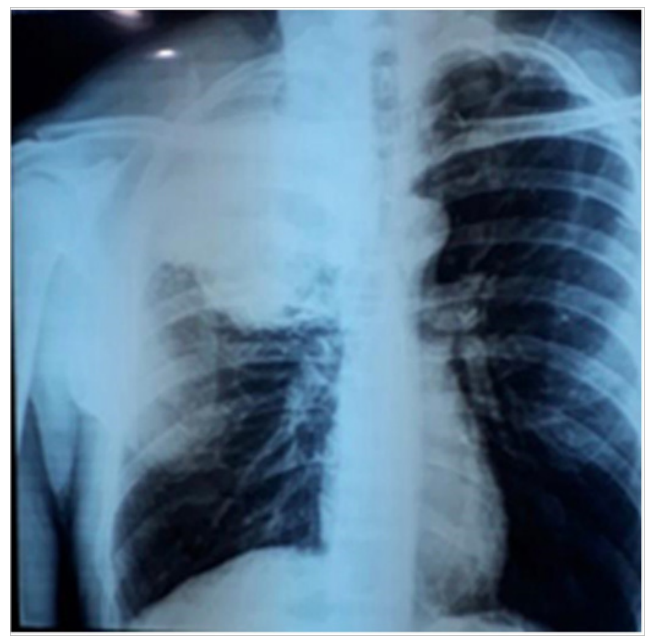

Figure I Chest X-ray P-A view showing: Right upper and mid zonal well defined tumor mass.
Volume 6 Issue 4 - 2019

Mohammad A Alim,' Dina Abo Alam, ${ }^{2}$ Yaser El Sayed, ${ }^{3}$ Amr Abdellateef, ${ }^{4}$ El Sayed Al Ghareeb, ${ }^{5}$ Mohammad Nafee, ${ }^{5}$ Mohammad El Sayed, ${ }^{5}$ Sami Ba Baker, ${ }^{5}$ Mohammad Eid, ${ }^{6}$ Suzan A Mageed, ${ }^{6}$ Sahar El Sayed ${ }^{7}$

'Cairo University, Egypt

${ }^{2}$ Abbasia Pulmonary Hospital, Egypt

${ }^{3}$ Military Medical Academy, Egypt

${ }^{4}$ Mansoura University, Egypt

${ }^{5}$ Department of Thoracic Surgery, Egypt

${ }^{6}$ Department of Chest Medicine, Egypt

${ }^{7}$ Department of Pathology, Egypt

Correspondence: Mohammad A Alim, Professor of Cardio Thoracic Surgery at Kaser Al Aini Faculty of Medicine, Cairo University, Egypt Email cardio_thorcic20I I@yahoo.com

Received: November 20, 2019 | Published: November 29, 2019

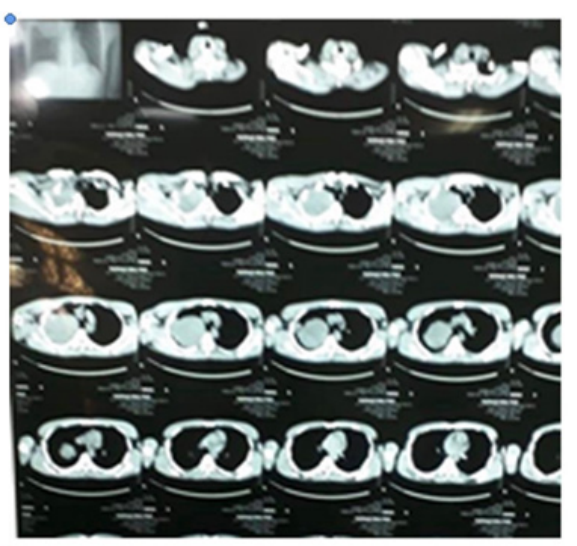

Figure 2 Mediassnal window of CT chest showing right upper lobe mass.

Preoperaave fiber opac bronchoscoy showed no endobroncheal pathology. Also the broncho-alveolar lavage was negative for both AFB and malignant cells. Preoperaave CT needle guided biopsy revealed a biphasic pulmonary blastoma with both epithelial and mesenchymal components. Preoperaave CT abdomen and bone scinagraphy revealed no evidence of distant metastasis (Figure 3).

The patient was referred to the Thoracic Surgery Department at our hospital for resecaon of the pulmonary blastoma affecang the right upper lung lobe. General anesthesia was conducted via double lumen end tracheal tube for one lung anesthesia. The patient was poisoned in the lateral decubitus posiaon with his right side up. Standard right postero-lateral thoracotomy in the fifih space was done. The tumor mass was seen and felt involving the enare right upper lung lobe and sparing both the middle and lower lung lobes. The mass was well circumscribed, lobulated with firm to hard texture. Classic right upper lobectomy was done. After closure of the bronchial stump with 
simple interrupted Vicryl 20sutures, the stump was covered using a pedicled intercostal muscle flap as our standard technique in cases of malignancy and TB to guard against postoperaave bronch-pleural fistula. Postoperaave pathology report confirmed the diagnosis of high grade biphasic pulmonary blastoma with free bronchial margin, free pleural assue and negative mediasanal lymph nodes for metastasis (Figure 4). The postoperaave course of the patient was unevennul. Afier removal of the satchels; the patient was referred to the Cancer Institute of Cairo University for evaluaaon and the possibility of post lobectomy chemotherapy and / or radiotherapy (Figure 5).

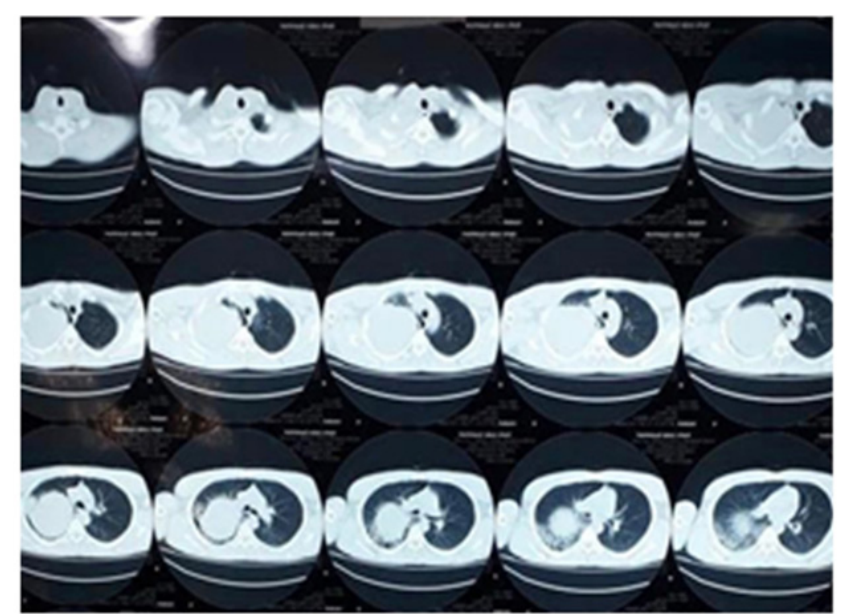

Figure 3 Pulmonary window of CT chest showing the right upper lobe tumor mass.

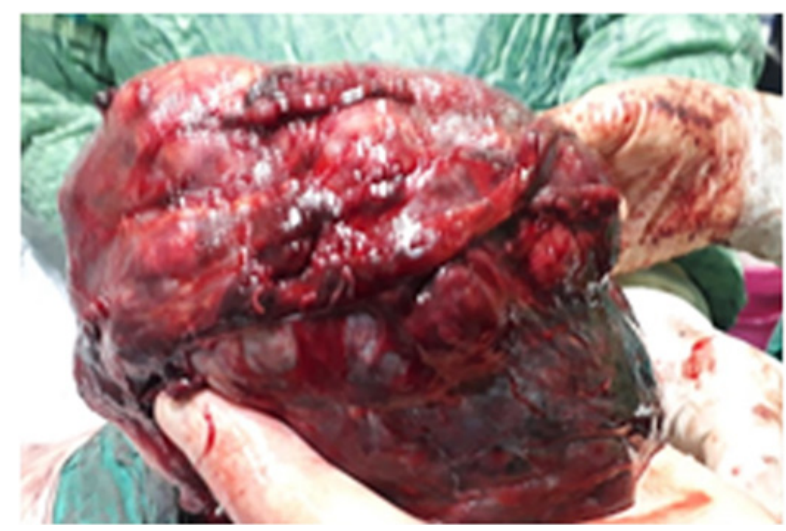

Figure 4 The right upper lobe showing the lobulated tumor mass.

\section{Discussion}

Pulmonary blastoma is a rare primary lung tumor occurring mainly in adults. The incidence is 0.25 to $0.5 \%$ of all primary lung tumors. ${ }^{3}$ The tumor was first described by Barree and Barnard in 1945, and it was termed by Barnard as "embryoma". ${ }^{4}$ The term "blastoma" was suggested by Spencer in 1961 because the pathogenesis of that tumor was believed to be similar to Wilms' tumor or nephoblastoma. ${ }^{5}$ The World Health Organization (WHO) had classified pulmonary blastomas into three categories according to the histopathology, the first type is pulmonary blastoma which is biphasic, the second type is pleura pulmonary blastoma which is monophonic and occurs commonly in childhood and the third type is the well differensated fetal adenocarcinoma (WDFA). ${ }^{6}$

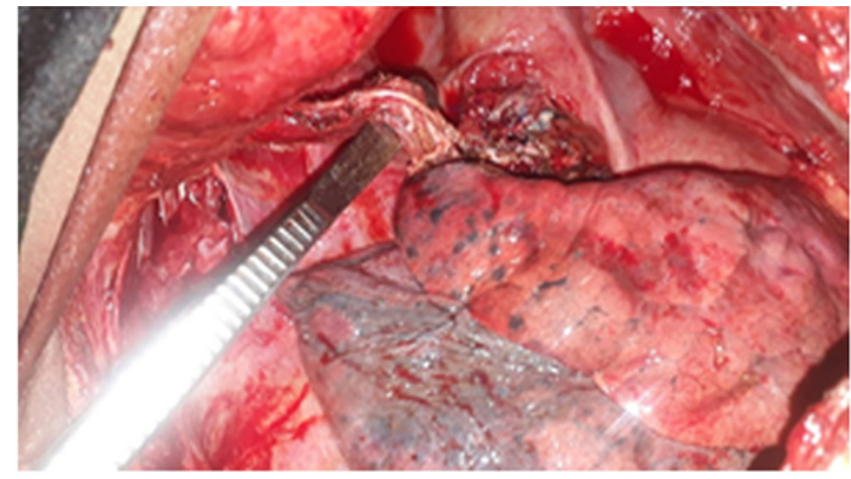

Figure $\mathbf{5}$ Intercostal muscle flap covering the bronchial stump.

The aesology and predisposing factors are not ssll fully understood. But, in the literature, there is strong evidence showing the correlation between cigarette smoking and pulmonary blastoma. ${ }^{7}$ Our patient was a smoker of one pack per day for more than 15 years. The peak incidence of biphasic pulmonary blastoma is in the fourth decade of life. About $30 \%$ of cases occurring in children and the tumor is known as pleura pulmonary blastoma. ${ }^{8}$ The age of our patient at the same of present son was 37 years old. Some groups reported a male predominance while others did not, ${ }^{9}$ Approximately $60 \%$ of patients are symptomaac. ${ }^{10}$. Usually biphasic pulmonary blastoma is located in the periphery of the lung, while $25 \%$ present with end bronchial tumor. ${ }^{11}$. Our patient was a male who complained of blood anged sputum and the tumor was proved by pre and postoperaave histopathology to be a biphasic peripheral pulmonary blastoma.

The radiological appearance of pulmonary blastoma is usually a solitary pulmonary nodule or a mass with a smooth margin due to the desmoplasac changes surrounding the tumor. Rarely the tumor cavitates, calcified or be mulaple. ${ }^{12}$ Preoperaave assue diagnosac procedures e.g. bronchoscopy, mediasanoscopy, CT needle guided biopsy usually cannot diagnose pulmonary blastome due to lack of cellular material and extensive necrosis of the tumor. ${ }^{13}$ In our patient CT guided biopsy could diagnose the tumor to be biphasic blastoma and this histopathology was confirmed by the postoperaave histopato pathological examination. The standard treatment of pulmonary blastoma consists of surgical resecaon..$^{14}$ Our patient had a resectable tumor and a right upper lobectomy was performed.

Due to the lack of data, adjuncave therapy with chemotherapy and / or radiotherapy is sall controversial. ${ }^{9}$ Our patient was referred to Cancer Institute of Cairo university for further evaluaaon of his need for adjuncave therapy or not. The prognosis of pulmonary blastoma is poor regardless of the histology. The overall 5 years survival was reported to be $16 \% .{ }^{15}$ Another study the researchers had reported that biphasic pulmonary blastomas have a poorer prognosis than the monophasic well differenaated fetal adenocarcinoma which have a beeer prognosis and a five years survival around $50 \% .{ }^{16}$ The factors contribuang to the unfavorable prognosis are the biphasic type, tumor recurrence, metastaac disease on presentation, tumor size more than $5 \mathrm{~cm}$, and frequent lymph node involvement. ${ }^{17}$

\section{Funding}

None. 


\section{Acknowledgments}

None.

\section{Conflicts of interest}

Authors declare that there is no conflict of interest.

\section{References}

1. Alahwal MS, Maniyar IH, Saleem F, et al. Pulmonary blastoma: rare primary lung malignancy. Case Rep Med. 2012;471613.

2. Walker RI, Suvarna K, Mathews. Case report: Pulmonary blastoma: presentaron of two atypical cases and review of the literature. $\mathrm{Br} J$ Radiol. 2005;78(929):437-440.

3. William D Travis, Andrew G, Nicholson, et al. Tumors of the lower respiratory tract. American Registry of Pathology. 1995:395-417.

4. Barnard WG. Embryoma of the lung. Thorax. 1952;7(4):299-301.

5. MJ Peacock, F Whitwell. Pulmonary blastoma. Thorax. 1976;31:197.

6. Brambilla E, Travis WD, Colby TV, et al. The new World Health Organizaron classificaron of lung tumors. Eur Respir J. 2001;18(6):1059-1068.

7. Zaidi A, Zamvar V, Macbeth F, et al. Pulmonary blastoma: medium term results from a regional center. Ann Thorac Surg. 2002;73(2):1572-1575.

8. Ozkaynak MF, Ortega JA, Gilsanz V, et al. Role of chemotherapy in pediatric pleuropulmonary blastoma. Med Pediatr Oncol. 1990;18:5361
9. Liman ST, Alrnok T, Topcu S, et al. Survival of biphasic pulmonary blastoma. Respir Med. 2006;100(7):1174-1179.

10. LeMense GP, Reed CE, Silvestri GA. Pulmonary blastoma: a rare lung malignancy. Lung Cancer. 1996;15(2):233-237.

11. Berho M, Moran CA, Suster S. Malignant mixed epithelial/mesenchymal neoplasms of the lung. Semin Diagn Pathol. 1995;12(2):123-139.

12. Lee HJ, Goo JM, Kim KW, et al. Pulmonary blastoma radiologic findings in five parents. Clin Imaging. 2004;28(2):113-118.

13. Robert J, Pache JC, Seium Y, et al. Pulmonary blastoma: report of five cases and idenrficaron of the clinical features suggesrve of the disease. Eur J Cardiothorac Surg. 2002;22:708-711.

14. Van Loo S, Boeykens E, Stappaerts I, et al. Classic biphasic pulmonary blastoma: A case report and review of literature. Lung Cancer. 2011;73(2):127-32

15. Adluri RKP, Boddu R, Ucar AM, et al. Pulmonary blastoma-a rare tumor with variable presentaron. Eur J Cardiothorac Surg. 2006;29(2):236239.

16. Koss MN, Holchholzer L, O'Leary T. Pulmonary blastomas. Cancer. 1991;67(9):2368-2381.

17. Cutler CS, Michel RP, Yassa M, et al. Pulmonary blastoma: case report of a parent with a 7-year remission and review of chemotherapy experience in the world literature. Cancer. 1998;82(3):462-457. 